\title{
Utilizing Epidemiological Investigations to Optimize Management of Grape Black Rot
}

\author{
Lisa Emele Hoffman and Wayne F. Wilcox
}

Department of Plant Pathology, Cornell University, New York State Agricultural Experiment Station, Geneva 14456. Current address of L. E. Hoffman: Department of Plant Pathology, University of California, Davis 95616. Accepted for publication 12 February 2002.

The severity of a plant disease epidemic is determined by the interaction of a susceptible host, a virulent pathogen, and the environment. However, these factors do not remain optimal for disease development over the course of an entire season. In addition to the vagaries of weather, the susceptibility of important host tissues and the availability of pathogen inoculum may be transitory. Furthermore, various cultural practices, including those that provide sanitation, may affect the severity of the outcome, as may variable fungicide programs. Human intervention must be timely and based on a comprehensive understanding of the epidemiology of the disease if we are to implement efficient and effective management strategies.

Black rot of grape is caused by the ascomycete Guignardia bidwellii (Ellis) Viala \& Ravaz (anamorph: Phyllosticta ampelicida (Englem.) van der Aa), which produces both ascospores and conidia in infected fruit that have mummified and overwintered in the vineyard. Ascospores are the principal form of primary inoculum, although conidia from overwintered mummies and cane lesions $(2,12)$ also may contribute to primary infections. Conidia are formed within pycnidia in the resulting lesions and constitute the secondary inoculum. Both types of spores are released during rain events, reportedly throughout the spring and summer $(3,4)$, and require free water for germination and infection (13).

Although black rot does little damage to the overall health of the vine (10), the disease can lead to substantial fruit damage in humid production regions if not properly managed. Even when losses in yield are low, black rot still must be managed to prevent the build-up of inoculum for the following year. Cultural practices also may impact the quantity and quality of overwintering inoculum. For instance, mechanical hedging is a nonselective dormant pruning practice that can retain overwintering inoculum within the trellis, which otherwise would be selectively removed during hand pruning. Although some eastern vineyardists are using this technique to save on labor costs, preliminary evidence (1) suggested that without supplementary sanitation measures, it might exacerbate black rot, although this was not studied in the context of disease management programs.

Application of fungicides is the primary tactic used to control black rot in most commercial vineyards. In the United States, the most effective materials for black rot management are the steroldemethylation inhibitor (DMI) fungicides, myclobutanil and tebuconazole. The strobilurin fungicides also provide very good control, and because some members of this class have the advantage

Corresponding author: L. E. Hoffman; E-mail address: lemhoffman@ucdavis.edu

Publication no. P-2002-0417-010

(C) 2002 The American Phytopathological Society of being active against Plasmopara viticola (downy mildew) in addition to Uncinula necator (powdery mildew) and G. bidwellii, they commonly are used during the bloom and early postbloom periods when control of all three diseases is critical.

Prior to the start of this work, recommendations typically suggested fungicides be applied every 10 to 14 days from approximately $10 \mathrm{~cm}$ of shoot growth until the berries reach $8^{\circ}$ Brix (percent soluble solids) (11), i.e., from approximately middle May until middle August in the Finger Lakes region of New York. This approach may require as many as seven or eight fungicide applications per season, and is based upon the largely unproven assumptions that (i) control of prebloom foliar infections is necessary to limit secondary inoculum to levels that are controllable on the fruit; and (ii) fruit remain susceptible to infection for up to 10 weeks after bloom. Although reduced spray programs based upon curative sprays following a forecasted infection event (13) have been tested successfully $(3,6)$, technical constraints on rapidly applying postinfection sprays have limited the commercial acceptance of such strategies.

Therefore, the objective of this research was to determine the critical period to fungicidally manage black rot and the factors that influence it, such as age-related resistance of grape berries, sanitation, inoculum dynamics, and weather. An additional objective was to examine and compare the postinfection and antisporulant properties of two commercial fungicides commonly used to control black rot, i.e., the DMI fungicide, myclobutanil, and the strobilurin fungicide, azoxystrobin.

\section{MATERIALS AND METHODS}

Period of fruit susceptibility. Fruit of Vitis vinifera 'Chardonnay' and 'Riesling' were inoculated weekly with a conidial suspension of G. bidwellii from bloom until 8 weeks later in both 1999 and 2000. Fruit of $V$. ×labruscana 'Concord' were inoculated on the same dates, but because 'Concord' vines bloomed earlier than those of the other two varieties, the first inoculation was performed 1 week after bloom. At dusk, 10 clusters per four replicate vines of each variety were inoculated with a hand-held atomizer until runoff and bagged overnight to maintain the moisture needed for infection (13). The number of symptomatic berries per inoculated cluster was assessed every 2 days in the field beginning 11 or 13 days after inoculation. To minimize the opportunity for natural secondary spread within the inoculated fruit, clusters were harvested 21 days after inoculation and the number of symptomatic and the total number of berries per cluster were counted, unless little or no disease had developed. In these instances, fruit were left to incubate on the vine for another 1 to 2 weeks, during which time periodic disease assessments were conducted in the 
field, and then fruit were harvested and evaluated as above. An analysis of variance was performed on the (arcsine-transformed) percentage of symptomatic berries per cluster determined during the final disease assessment and the treatment means were separated using the Waller-Duncan k-ratio $t$ test $(P \leq 0.05)$.

Effect of fruit age on length of incubation period. Because temperature influences the temporal duration of the incubation period (9), a measure of accumulated degree hours was used to compare the incubation periods that occurred under different conditions. For each replication of the cultivar $\times$ fruit age combination, the percentages of symptomatic berries determined during each disease assessment were transformed to probits and regressed against the number of degree hours (base $0^{\circ} \mathrm{C}$ ) accumulated subsequent to inoculation. For the determination of degree hours, mean hourly temperatures were calculated by averaging the readings taken each minute by a datalogger (Campbell CR10; Campbell Scientific, Logan, UT) located in the vineyard. Because newly symptomatic berries resulting from a single inoculation appeared over a period of 1 to 2 weeks following initial symptom expression, the incubation period was further defined as the number of degree hours accumulated when $50 \%$ of the final disease incidence was evident $\left(\mathrm{DH}_{50}\right)$, as calculated from the preceding regression equations.

Effect of inoculum availability, sanitation, host phenology, and prevailing weather on the efficacy of different spray timings. To study the epidemiology of black rot within the context of disease management, field trials were conducted from 1995 to 1999 in a hand-pruned vineyard of the Vitis interspecific hybrid 'Aurore' that was located in Dresden, NY, and had a history of moderate disease development. Additionally, in 1998 and 1999, the effect of poor sanitation resulting from mechanical pruning with little or no hand follow-up was also studied in a second vineyard located in Naples, NY. This vineyard, consisting of $V$. xlabruscana 'Delaware', had a history of severe disease losses and was mechanically pruned for several years prior to the start of this trial. At this site, a split-plot design was used in which mummies retained after mechanical pruning were left in the trellis in half the plots, and in the other half, all mummies were removed from the vines and dropped to the ground beneath them to simulate the form of sanitation associated with hand pruning. At both vineyards, different spray timing regimes, constructed by varying the number and timing of applications of the fungicide myclobutanil (112 g/ha) at 2-week intervals, were imposed on four replicate, three-vine spray plots per treatment. The timing regimes consisted of combinations of the following phenologically based applications: 10- (spray 1) or 25-cm shoot growth (spray 2), immediately prior to bloom (spray 3 ), or 2- (spray 4), 4- (spray 5), or 6-weeks postbloom (spray 6).

Disease progress, prevailing weather conditions, and inoculum availability were monitored throughout the season in both vineyards. Campbell CR10 dataloggers recorded rainfall, the average hourly temperature, and leaf wetness, from which the occurrence of black rot infection periods was calculated according to the criteria of Spotts (13). Airborne ascosporic inoculum was monitored with Burkhard 7-day spore traps (Burkhard Manufacturing Co., Rickmansworth, Hertfordshire, England). The maturation of both ascospores and conidia was monitored by collecting overwintered mummies periodically from the vineyard, soaking them in sterile distilled water, and counting the number of each spore type recovered with the aid of a hemacytometer. Mummies were collected from both the trellis and the ground at Naples. Disease progress was monitored weekly by assessing the percent area infected on all leaves of 10 shoots and on 50 clusters per plot. These disease assessments also provided an estimate of the relative presence of secondary inoculum, which developed in both the infected leaves and fruit. Fifty clusters were harvested at the end of the season from the center two-thirds of each treatment plot and examined individually to determine the percentage of symptomatic berries per cluster. Arcsine-transformed means of the percentage of symptomatic clusters and berries at Dresden and Naples, respectively, were subjected to analysis of variance, and the treatment means were separated using the Waller-Duncan k-ratio $t$ test $(P \leq 0.05)$.

Postinfection activities of myclobutanil and azoxystrobin. The postinfection activities of myclobutanil and azoxystrobin were determined by inoculating open-pollinated $V$. vinifera 'Riesling' seedlings (containing four to five leaves) with $2 \times 10^{4}$ conidia per $\mathrm{ml}$ and applying commercially formulated myclobutanil (60 mg/liter), azoxystrobin (128 mg/liter), or water either 2, 4, 6, 8 , or 10 days later. The oldest still-expanding leaf and the leaf immediately above that, marked at the time of inoculation, were assessed 25 days after inoculation for the number of lesions per leaf, area infected per leaf, pycnidial density, and the number of spores recovered per pycnidium. Each measured response was averaged over the two leaves assessed per plant and then over the eight replicate seedlings per treatment. For each variable, the percentage of disease control relative to the check was calculated and the efficacies of the two compounds were compared using a twoway $t$ test.

The extent of the postinfection activity of myclobutanil was further examined by inoculating seedlings with $2 \times 10^{4}$ conidia per $\mathrm{ml}$ and treating them with myclobutanil either 9, 11, 13, or 15 days later. The black rot lesions apparent immediately prior to each fungicide application were identified with a permanent ink marker. Lesions with and without pycnidia were marked with different color markers. The plants were assessed as described above and the measured responses were averaged over the eight replicate seedlings per treatment at each leaf position.

\section{RESULTS AND DISCUSSION}

Period of fruit susceptibility. In 1999, V. vinifera 'Riesling' and 'Chardonnay' berries were highly susceptible to G. bidwellii from 1 to 4 weeks after bloom and somewhat less disease developed when clusters were inoculated at midbloom (approximately 40 to $70 \%$ versus 20 to $25 \%$ of the berries were symptomatic 21 days after harvest, respectively [Fig. 1]). When 5- and

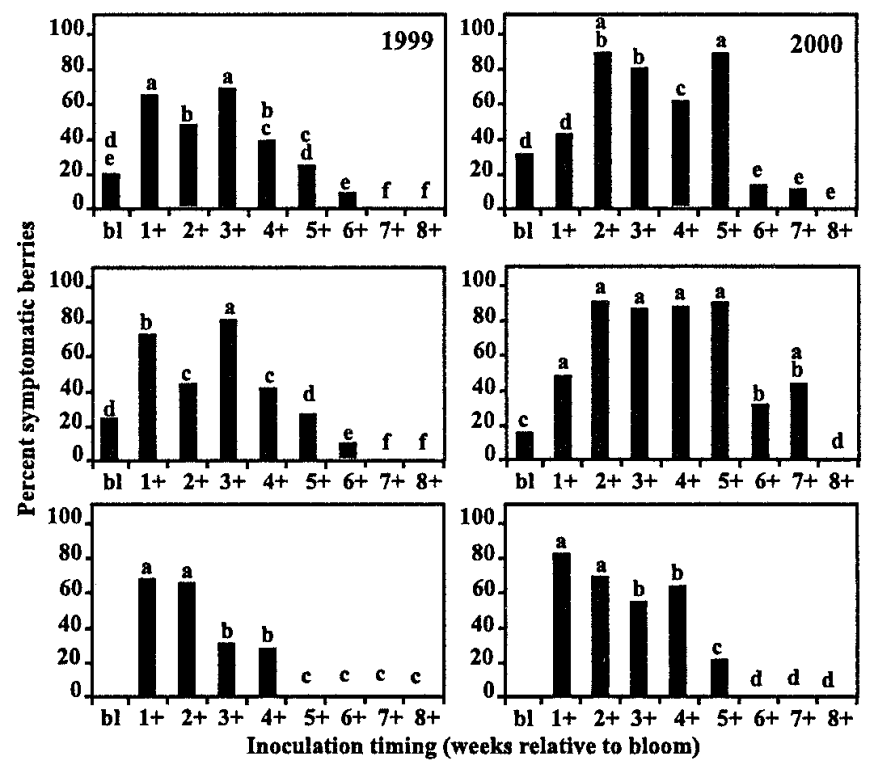

Fig. 1. Susceptibility to Guignardia bidwellii among fruit of cvs. Chardonnay, Riesling, and Concord at different ages. Fruit were inoculated with a spore suspension containing $2 \times 10^{5}$ conidia per ml weekly from bloom until 8 weeks later in 1999 and 2000 (except for 'Concord' fruit, which were first inoculated 1 week after bloom). Means (bars) not sharing a common letter are significantly different $(P \leq 0.05)$ as determined by the Waller-Duncan $\mathrm{k}$ ratio $t$ test. 
6-week-old fruit were inoculated, approximately 10 and $<1 \%$ of the berries were symptomatic 21 days after inoculation (data not shown), respectively, but the frequency of symptomatic berries increased to approximately 30 and $10 \%$, respectively, after an additional 7 days of incubation in the field. Similar results were obtained in 2000, although the period of maximum susceptibility was from 2 to 5 weeks after bloom (65 to $90 \%$ frequency of symptomatic berries 21 days after inoculation), and berries retained some susceptibility until 7 weeks after bloom (Fig. 1). When 6 - and 7-week-old fruit were inoculated, $<1 \%$ of the berries became symptomatic within 21 days of inoculation (data not shown), but after an additional 14 days of incubation on the vine, 13 and $10 \%$ of 'Chardonnay' berries and 32 and $45 \%$ of 'Riesling' berries were symptomatic, respectively.

The period of susceptibility for $V$. xlabruscana 'Concord' was shorter, lasting only 4 to 5 weeks after midbloom (Fig. 1). In 1999, approximately $70 \%$ of the berries developed symptoms within 21 days when inoculated 1 and 2 weeks after midbloom, with the frequency of diseased berries falling significantly $(P \leq$ 0.05 ) to about $30 \%$ when fruit were inoculated 3 and 4 weeks after midbloom. No disease developed within 28 days when berries were inoculated 5 weeks after midbloom. In 2000, fruit were highly susceptible when inoculated from 1 to 4 weeks after bloom (60 to $90 \%$ of the fruit became symptomatic within 21 days of inoculation), but only $25 \%$ of 5 -week-old fruit became symptomatic despite allowing them to incubate on the vine for 5 weeks (Fig. 1). This period of 'Concord' fruit susceptibility was reasonably consistent with that observed in Michigan by Ferrin and Ramsdell $(4,5)$, although these authors noted a distinct peak in susceptibility at the midbloom stage and found that a small proportion of berries became symptomatic when inoculated with conidia through 10 weeks after bloom. Our results, confirmed in the field trials reported subsequently, suggest that fungicidal protection of fruit is not necessary beyond 4 to 7 weeks after bloom, depending on the cultivar and year, even when inoculum is present.

Effect of fruit age on length of incubation period. Although some literature indicates that black rot infections generally appear within 10 to 14 days after infection (14), we found that the incubation period can be much longer as berries begin to acquire ontogenic or age-related resistance. That is, such resistance was manifested not only as a decline in the percentage of berries that developed black rot as fruit aged, but also as an increase in the incubation period for those fruit that did become diseased. For instance, when 'Chardonnay' and 'Riesling' fruit were inoculated from bloom until 4 weeks later in 1999, symptoms were apparent

TABLE 1. Effect of fungicide timing on black rot incidence on clusters of the Vitis interspecific hybrid 'Aurore' at Dresden, NY, from 1995 to 1999

\begin{tabular}{lrrrrr}
\hline & \multicolumn{5}{c}{ \% Symptomatic clusters $^{\mathrm{z}}$} \\
\cline { 2 - 6 } Spray timing $^{\mathrm{y}}$ & 95 & 96 & 97 & 98 & 99 \\
\hline Unsprayed check & $99 \mathrm{a}$ & $60 \mathrm{a}$ & $45 \mathrm{a}$ & $82 \mathrm{a}$ & $85 \mathrm{a}$ \\
$1,2,3,4,5$ & $5 \mathrm{c}$ & $1 \mathrm{~cd}$ & $1 \mathrm{~b}$ & $0 \mathrm{c}$ & $1 \mathrm{~d}$ \\
$1,2,3,4$ & $44 \mathrm{~b}$ & $4 \mathrm{~cd}$ & $0 \mathrm{~b}$ & $0 \mathrm{c}$ & n.i. \\
$2,3,4,5$ & $0 \mathrm{c}$ & $0 \mathrm{~d}$ & $0 \mathrm{~b}$ & $0 \mathrm{c}$ & $0 \mathrm{~d}$ \\
$3,4,5,6$ & n.i. & n.i. & $0 \mathrm{~b}$ & $0 \mathrm{c}$ & n.i. \\
$3,4,5$ & $3 \mathrm{c}$ & $0 \mathrm{~d}$ & $0 \mathrm{~b}$ & $0 \mathrm{c}$ & $0 \mathrm{~d}$ \\
3,4 & n.i. & $5 \mathrm{c}$ & $2 \mathrm{~b}$ & $0 \mathrm{c}$ & $2 \mathrm{~d}$ \\
4,5 & $42 \mathrm{~b}$ & $4 \mathrm{~cd}$ & $2 \mathrm{~b}$ & $0 \mathrm{c}$ & $3 \mathrm{~d}$ \\
$1,2,3$ & $86 \mathrm{a}$ & $27 \mathrm{~b}$ & $4 \mathrm{~b}$ & $17 \mathrm{~b}$ & $14 \mathrm{c}$ \\
1,2 & n.i. & n.i. & n.i. & n.i. & $41 \mathrm{~b}$ \\
\hline
\end{tabular}

${ }^{\mathrm{y}}$ Myclobutanil (112 g/ha) was applied to indicated treatments at the following approximate phenological stages: $1=10-\mathrm{cm}$ shoot growth; $2=$ $25-\mathrm{cm}$ shoot growth; $3=$ immediate prebloom; and 4, 5, and $6=2,4$, and 6 weeks after immediate prebloom, respectively.

${ }^{\mathrm{z}}$ Values represent the means from four replicate plots per treatment. Means within a column not followed by a common letter are significantly different $(P \leq 0.05)$ as determined by the Waller-Duncan k-ratio $t$ test. n.i. $=$ treatment not included in the year indicated. by the disease assessment at 13 days, or approximately 7,500 to 8,000 DH, after inoculation. However, when 5- and 6-week-old fruit were inoculated, the first symptoms were not apparent until the disease assessments 15 and 21 days after inoculation, or 9,000 and 11,000 DH, respectively. A similar delay in symptom appearance on older fruit was observed for all three cultivars in both years.

The relationship between fruit age and length of incubation period was similarly evident in comparisons of $\mathrm{DH}_{50}$ values. As the fruit of each cultivar aged, a sharp increase in $\mathrm{DH}_{50}$ values occurred at times that corresponded to those at which the frequency of symptom development declined sharply. For instance, in 2000, the $\mathrm{DH}_{50}$ was typically between 8,000 and 9,000 when 'Chardonnay' and 'Riesling' fruit were inoculated from bloom until 5 weeks later, but increased to $>13,000$ when less-susceptible 6- and 7-week-old fruit were inoculated. On 'Concord', the $\mathrm{DH}_{50}$ similarly increased by nearly $50 \%$ when less-susceptible fruit were inoculated 5 weeks after bloom compared with when highly susceptible 3- and 4-week-old fruit were inoculated.

Improved knowledge concerning the duration of black rot incubation periods, particularly their extension as berries age, has practical implications when it becomes necessary to attribute disease occurrence to a specific weather event. This applies not only to researchers examining the epidemiology and management of this disease, but also to pest management advisors attempting to diagnose the precise cause of unexpected control failures.

Interaction of host phenology, inoculum availability, sanitation, prevailing weather, and fungicide application timing on disease control. The efficacy of different phenologically based fungicide timing regimes was influenced by specific weather events,
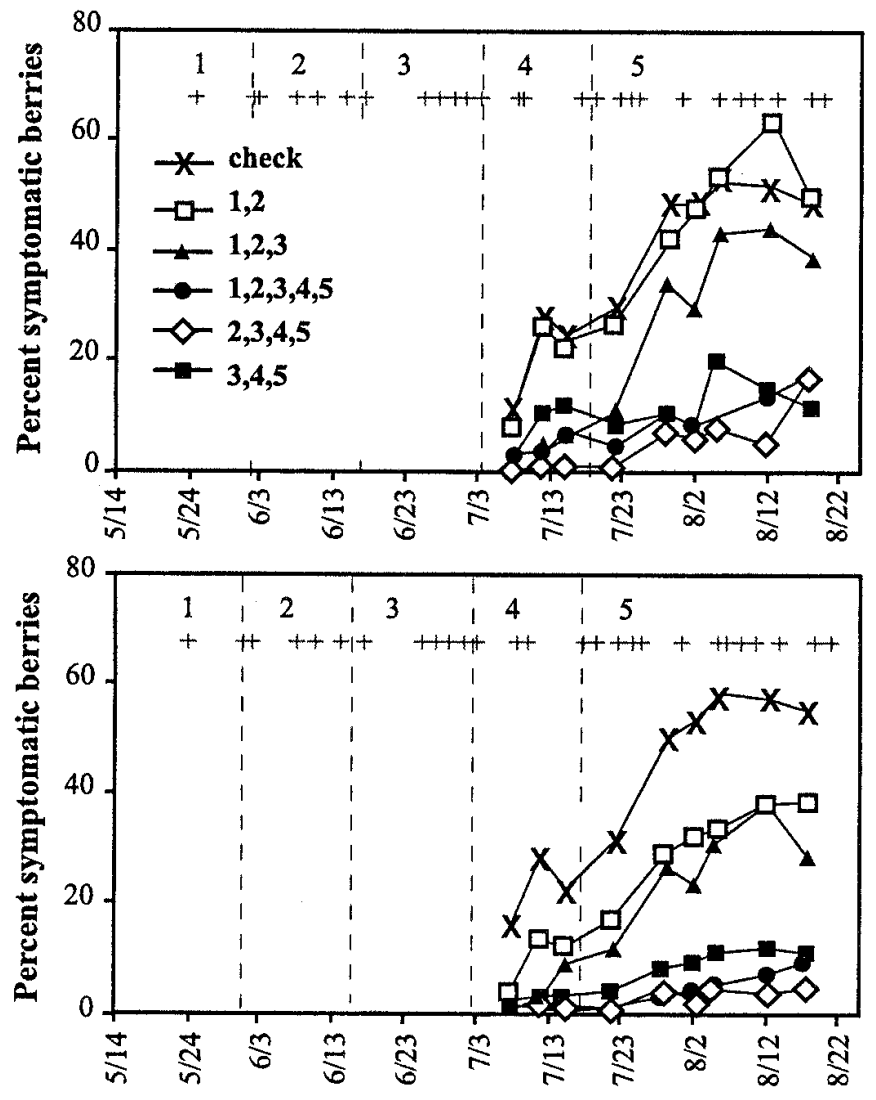

Assessment date

Fig. 2. Disease progress on the fruit subjected to different fungicide timing regimes at Naples in 1999. Mummies were retained in the trellis (top) or dropped to the ground beneath the vines (bottom) prior to the growing season. The dashed lines indicate the timing of fungicide applications (as designated by the numerals to the right of each line), and the plus signs indicate the occurrence of infection periods. 
the availability of primary and secondary inoculum, and horticultural practices that affected sanitation. In the hand-pruned Dresden vineyard, three sprays of myclobutanil applied immediately prior to bloom plus 2 and 4 weeks later (i.e., sprays 3 to 5) provided 97 to $100 \%$ control of disease incidence on clusters in all 5 years the trial was conducted (Table 1). When any of these critical sprays were omitted, and inoculum and weather conditions conducive to disease occurred, control was compromised. For instance, in 1995, 97\% control of fruit infections was obtained when the three critical sprays were applied (i.e., sprays 3, 4, and 5), but control was reduced to $56 \%$ when spray 5 was omitted and only sprays 1 through 4 were applied (Table 1). This loss of control was associated with three infection periods that occurred during the 8 days before spray 5 and with five infection periods that occurred during the 2 weeks immediately after it. In some years, however, application of just the first postbloom spray (spray 4) plus one more, 2 weeks either before or after it, controlled fruit infections adequately (Table 1).

In the hand-pruned Dresden vineyard, 71 to $91 \%$ of the season's ascospores were trapped prior to the immediate prebloom spray and 95 to $100 \%$ were trapped by 2 weeks later, depending on the year. However, restricting fungicide applications to account only for the anticipated period of major ascospore discharge yielded erratic results, e.g., application of myclobutanil from 4 weeks prebloom through the immediate prebloom stage provided 13 to 91\% control of diseased clusters at harvest if subsequent postbloom sprays were omitted (Table 1). In contrast, targeting sprays to protect fruit during the period of maximum susceptibility to black rot consistently provided outstanding control, and applying additional sprays to control foliar infections during the 4 weeks prior to bloom provided no further benefit (Table 1).

At Naples in 1998, approximately $60 \%$ of the season's ascospores were trapped during two infection periods prior to spray 1 and $95 \%$ were trapped by 2 weeks after bloom, similar to the pattern observed at the Dresden site. However, in 1999, the period during which ascospores were trapped was delayed and prolonged relative to previous observations; ascospores were not trapped prior to spray 1 and only $60 \%$ of the season's totals were trapped by 2 weeks after bloom. When mummies were collected from the ground and soaked in sterile distilled water, peaks of spore recovery were observed around bloom, at which time 12,000 to 40,000 ascospores and 80,000 to 800,000 conidia were recovered per mummy. No spores of either type were recovered in either year when mummies were collected from the ground later than 1 to 2 weeks after bloom. In contrast, when mummies were collected from the trellis, large numbers of both ascospores and conidia (as many as 70,000 and 800,000 per mummy, respectively) were detected throughout the summer until harvest.

Mummy placement also affected disease development. The frequency of fruit rot at harvest was increased by 20 to $>100 \%$ when mummies were retained in the trellis relative to when they were dropped to the ground beneath the vines. The effect of this sanita- tion treatment was far more pronounced when critical postbloom sprays were omitted than it was when they were applied. For instance, when only three prebloom sprays were applied in 1998, 51 and $84 \%$ of the berries were infected at harvest when mummies were removed from or retained in the trellis, respectively, whereas these respective frequencies were reduced to 18 and $21 \%$ when sprays were applied immediately prior to bloom plus 2 and 4 weeks later. Perhaps because inoculum pressure was greater at Naples than at Dresden, this regime of myclobutanil applied immediately before bloom plus 2 and 4 weeks later provided only 76 to $81 \%$ control of fruit rot at harvest across both years and sanitation treatments at the Naples site, whereas it provided virtually complete control in all five seasons at Dresden. In contrast to Dresden, application of spray 2 in addition to the immediate prebloom and two postbloom sprays significantly $(P \leq 0.05)$ improved disease control at harvest irrespective of mummy placement in 1998 (88 and $84 \%$ control of berry infections when mummies were removed from or retained in the trellis, respectively), but only in plots where mummies were removed to the ground in $1999(91 \%$ control versus $64 \%$ when mummies were retained in the canopy). When only the first two or three prebloom sprays were applied in 1999 , the frequency of berry rot at harvest was reduced significantly $(P \leq 0.05)$ in plots where mummies were dropped to the ground (as it was in the hand-pruned Dresden plots subjected to this same treatment) (Table 1), whereas these treatments provided no control when mummies were retained in the trellis (Fig. 2). It is likely that when mummies were retained in the trellis, the abundant inoculum that they produced throughout the postbloom period negated the positive effect of reducing secondary inoculum from leaf lesions that was provided by the prebloom sprays. Retaining mummies in the trellis rather than dropping them to the ground not only extended the period of inoculum availability, but also increased the likelihood that conidia-10-fold as prevalent as ascospores-would be splash dispersed to susceptible fruit. Splash dispersal occurs over short distances and is greatly facilitated by gravity (8).

The contrast between our results from the Dresden versus the Naples vineyard illustrates the critical influence on black rot management programs exerted by variable levels of primary inoculum and efforts to mitigate it via appropriate sanitation measures. Although the immediate prebloom plus two postbloom sprays will probably provide sufficient control in most vineyards, application of an additional prebloom spray (e.g., our spray 2) may be warranted in a high-inoculum vineyard such as Naples, where significant numbers of leaf lesions initiated prior to bloom may provide excessive secondary inoculum while fruit are highly susceptible to infection during the early postbloom period. In contrast, our results in some years at Dresden and those of Gadoury et al. (6) suggest that sprays sometimes may be truncated as early as 2-weeks postbloom, although the criteria by which such a minimalist approach may safely be employed have yet to be determined. Also, similar to the preliminary results of Becker and Pearson (1),

TABLE 2. Comparative postinfection and antisporulant activities of myclobutanil and azoxystrobin against Guignardia bidwellii ${ }^{\mathrm{w}}$

\begin{tabular}{|c|c|c|c|c|c|c|}
\hline \multirow[b]{3}{*}{ Days postinoculation } & \multicolumn{6}{|c|}{ Control $(\%)$ relative to check treatment } \\
\hline & \multicolumn{2}{|c|}{ Leaf area infected ${ }^{\mathrm{x}}$} & \multicolumn{2}{|c|}{ Pycnidial density } & \multicolumn{2}{|c|}{ Conidia/pycnidium ${ }^{z}$} \\
\hline & Myclobutanil & Azoxystrobin & Myclobutanil & Azoxystrobin & Myclobutanil & Azoxystrobin \\
\hline 2 & 100 & $78 *$ & - & $17 *$ & - & 85 \\
\hline 4 & 100 & $68 *$ & - & $61 *$ & - & $82 *$ \\
\hline 6 & 100 & $71 *$ & - & $24 *$ & - & $80 *$ \\
\hline 8 & 91 & 68 & 100 & $31 *$ & - & $81 *$ \\
\hline 10 & 74 & 63 & 98 & $17 *$ & 64 & $69 *$ \\
\hline
\end{tabular}

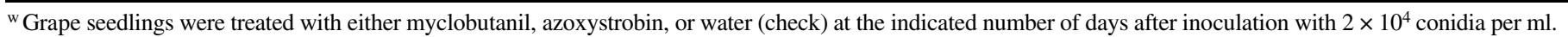

${ }^{x}$ Asterisks indicate significant differences between the two fungicides $(P \leq 0.05)$ as determined in two-way $t$ tests.

${ }^{y}$ Pycnidia per square millimeter of leaf tissue infected. Asterisks indicate significant differences $(P \leq 0.05)$ from $100 \%$ control as determined in a $t$ test.

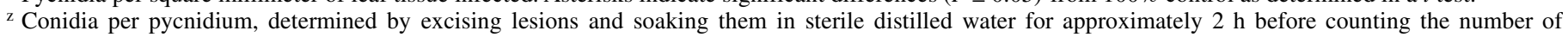
conidia recovered with the aid of a hemacytometer. Asterisks indicate significant differences $(P \leq 0.05)$ from $100 \%$ control as determined in a $t$ test. 
our results suggest that mechanical pruning following a significant outbreak of black rot appears to exacerbate future losses by retaining mummies within the trellis and altering the quantity, dynamics, and placement of primary inoculum in a manner that increases the severity of fruit infection.

Maintaining fungicidal protection of the fruit until 5\% soluble solids (approximately middle August in the Finger Lakes region of New York), as previously recommended (11), provided no better control than spraying only through 4-weeks postbloom (middle July) at either of our test locations, even though primary inoculum was available until harvest when mummies were retained in the trellis at Naples. Similarly, Jermini and Gessler (7) reported that no new fruit infections occurred later than middle July in a handpruned $V$. vinifera 'Merlot' vineyard in Switzerland despite continued inoculum availability and weather conditions conducive to black rot development. These results, combined with those from our inoculation studies, collectively suggest that fruit become resistant to G. bidwellii substantially earlier than previously suggested.

Comparative postinfection activities of myclobutanil and azoxystrobin. Myclobutanil applied from 2 to 6 days after inoculation (i.e., 9 to 5 days prior to the appearance of first symptoms) provided complete control of black rot on seedling foliage, and control of mean lesion area declined only moderately to 91 and $75 \%$ (relative to the check) following 8- and 10-day postinoculation treatments, respectively (Table 2). No pycnidia were found in the few lesions that did form in the 8-day postinoculation treatment. Similarly, pycnidium formation in lesions that developed after the 10-day postinoculation treatment was reduced by $98 \%$ relative to the check treatment, and mean spore recovery from each of these pycnidia was reduced by $64 \%$ relative to the check (Table 2). Myclobutanil applied beyond 10 days after inoculation provided $<50 \%$ control of disease severity, but provided excellent control of pycnidium formation when it was applied prior to lesion appearance.

In comparison to myclobutanil, azoxystrobin applied 2 to 8 days after inoculation provided significantly less control of the area infected per plant $(P \leq 0.001$ to 0.08 ) (Table 2$)$. Control of pycnidium formation ranged from 17 to $61 \%$, although this effect was erratic and inconsistent among application times and experiments. Azoxystrobin, however, did provide consistent reduction of conidium formation within those pycnidia that developed. The degree of reduction decreased over time from $85 \%$ when applied 2 days after inoculation to $69 \%$ when applied 10 days later (Table 2 ). Increasing the inoculum concentration by nearly 2 orders of magnitude to $1 \times 10^{6}$ conidia per ml significantly reduced the control provided by azoxystrobin at each application time tested but did not affect the postinfection activity of myclobutanil.

The antisporulant activity of myclobutanil when applied prior to lesion appearance may explain why early season sprays of myclobutanil provided no additional control of fruit rot in the handpruned 'Aurore' vineyard, despite the preponderant release of primary inoculum prior to bloom, so long as this fungicide was applied immediately before bloom and in two subsequent sprays. It is likely that the immediate prebloom application of myclobutanil suppressed the production of conidia from previous ascosporic infections on leaves, which may have increased the efficacy of the sprays applied to the young fruit.

Knowledge of inoculum dynamics, the influence of host phenology on susceptibility to disease, and the activities of different fungicides facilitate the development of efficient disease management programs. The critical time for applying black rot fungicides appears to be from the immediate prebloom period until 4 weeks later. The benefit of earlier prebloom sprays and the safety of trun- cating postbloom sprays before this time appears to depend on inoculum levels in the vineyard and weather conditions suitable for disease development. Additionally, compound selection may also affect the efficacy of spray timing. For example, azoxystrobin currently is used by many New York growers in the immediate prebloom and early postbloom period critical for control of powdery mildew, downy mildew, and black rot because it is effective against DMI-resistant isolates of U. necator (16) and is highly effective against downy mildew (15), as well as being active against $G$. bidwellii. However, integrated management of multiple diseases often involves trade-offs. Azoxystrobin lacks the strong postinfection and antisporulant activity demonstrated by myclobutanil in our studies, and additional research is needed to confirm that it will provide the same level of control when used in similar programs.

\section{ACKNOWLEDGMENTS}

Funding assistance was provided by the NY Wine and Grape Foundation and the Viticulture Consortium-East. Much of this research was conducted in cooperation with D. M. Gadoury and R. C. Seem. We thank D. G. Riegel for the technical assistance provided.

\section{LITERATURE CITED}

1. Becker, C. M., and Pearson, R. C. 1993. Evaluation of cultural control strategies for managing black rot (Guignardia bidwellii) of grapes. (Abstr.) Phytopathology 83:1377.

2. Becker, C. M., and Pearson, R. C. 1996. Black rot lesions on overwintered canes of Euvitis supply conidia of Guignardia bidwellii for primary inoculum in the spring. Plant Dis. 80:24-27.

3. Ellis, M. A., Madden, L. V., and Wilson, L. L. 1986. Electronic grape black rot predictor for scheduling fungicides with curative activity. Plant Dis. 70:938-940.

4. Ferrin, D. M., and Ramsdell, D. C. 1977. Ascospore dispersal and infection of grapes by Guignardia bidwellii, the causal agent of grape black rot disease. Phytopathology 67:1501-1505.

5. Ferrin, D. M., and Ramsdell, D. C. 1978. Influence of conidia dispersal and environment on infection of grape by Guignardia bidwellii. Phytopathology 68:892-895.

6. Gadoury, D. M., Pearson, R. C., Seem, R. C., and Park, E. W. 1997. Integrating the control programs for fungal diseases of grapevine in the Northeastern United States. Vitic. Enol. Sci. 52:140-147.

7. Jermini, M., and Gessler, C. 1996. Epidemiology and control of grape black rot in southern Switzerland. Plant Dis. 80:322-325.

8. Madden, L. V. 1992. Rainfall and the dispersal of fungal spores. Adv. Plant Pathol. 8:39-79.

9. Northover, P. R. 1998. The relationship of the number of wetting periods and accumulated degree-days to sporulation of Guignardia bidwellii (Ellis) Viala and Ravaz in vineyards. M.Sc. thesis. Pennsylvania State University.

10. Price, B. S. 1892. Black rot of the grape: Life history. Pages 217-231 in: Treatment. Texas Agric. Exp. Stn. Bull. 32.

11. Ramsdell, D. C., and Milholland, R. D. 1988. Black rot. Pages 15-17 in: Compendium of Grape Diseases. R. C. Pearson and A. C. Goheen, eds. The American Phytopathological Society, St. Paul, MN.

12. Scribner, F. L., and Viala, P. 1888. Black rot (Laestadia bidwellii). Dep. Agric. Bot. Div. Bull. 7.

13. Spotts, R. A. 1977. Effect of leaf wetness duration and temperature on the infectivity of Guignardia bidwellii on grape leaves. Phytopathology 67:1378-1381.

14. Spotts, R. A. 1980. Infection of grape by Guignardia bidwellii-Factors affecting lesion development, conidia dispersal, and conidial populations on leaves. Phytopathology 70:252-255.

15. Wilcox, W. F., Riegel, D. G., and Wong, F. P. 1998. Evaluation of fungicide programs for control of downy mildew of grapes, 1997. Fung. Nemat. Tests 54:111.

16. Wong, F. P., and Wilcox, W. F. 2002. Sensitivity to azoxystrobin among isolates of Uncinula necator: Baseline distribution and relationship to myclobutanil sensitivity. Plant Dis. 86:394-404. 